\title{
Project Transcontainer
}

\author{
K. Boutilier \\ Plant Research International B. V., Wageningen, The Netherlands \\ Correspondence to: Dr. Kim Boutilier, Plant Research International (PRI), NL-6700 AA Wageningen, P. O. Box 16, The Netherlands, \\ Tel.: +31317 4771 67, Fax: +31317 4231 10, E-mail: kim.boutilier@wur.nl
}

Underlying the release of genetically modified (GM) plants is the public concern that transgenes may be transferred to conventional or organically grown varieties of the same crop or to wild relatives. This concern has stimulated interest in the development of biological containment technologies that will facilitate co-existence of GM crops with conventional and organic crops.
Transcontainer is a European Commission-funded Specific Targeted Research Project (STREP) in which the technical, environmental and socio-economic aspects of biological containment strategies and their implementation are examined. During my presentation I will outline the strategic goals and overall structure of the project, as well as provide an overview of the progress in the different work packages.

To access this journal online:

http://www.birkhauser.ch/JVL 